\title{
Application of 3D Reservoir Geological Model on Es1 Formation, Block Nv32, Shenvsi Oilfield, China
}

\author{
Ayman Al Rassas' ${ }^{1}$, Shaoran Ren1, Renyuan Sun1, Atif Zafar1,2, Safea Moharam³, Zhenliang Guan", \\ Alalimi Ahmed ${ }^{4}$, Mohammed Alomaisi ${ }^{5}$
}

${ }^{1}$ School of Petroleum Engineering, China University of Petroleum (East China), Qingdao, China

${ }^{2}$ Department of Petroleum Technology, University of Karachi, Karachi, Pakistan

${ }^{3}$ College of Computer Science, China University of Geosciences, Wuhan, China

${ }^{4}$ Faculty of Earth Resources, China University of Geosciences, Wuhan, China

${ }^{5}$ School of Chemistry and Environment, South China Normal University, Guangzhou, China

Email: alrassas1989@gmail.com

How to cite this paper: Rassas, A.A., Ren, S., Sun, R., Zafar, A., Moharam, S., Guan, Z., Ahmed, A. and Alomaisi, M. (2020) Application of 3D Reservoir Geological Model on Es1 Formation, Block Nv32, Shenvsi Oilfield, China. Open Journal of Yangtze Gas and Oil, 5, 54-72.

https://doi.org/10.4236/ojogas.2020.52006

Received: March 3, 2020

Accepted: April 4, 2020

Published: April 7, 2020

Copyright $\odot 2020$ by author(s) and Scientific Research Publishing Inc. This work is licensed under the Creative Commons Attribution International License (CC BY 4.0).

http://creativecommons.org/licenses/by/4.0/ (c) (i) Open Access

\section{Abstract}

Three-dimensional geological modeling of reservoirs is an essential tool to predict reservoir performance and improve the understanding of reservoir uniqueness in Es1 formation. The paper focuses on the use of petrel software to build three-dimensional reservoir geological model which characterizes and assesses block Nv32 that located in the west of the Shenvsi oilfield in the south of Cangzhou city, Hebei province of China, and has an oil-bearing area of $1.4 \mathrm{~km}^{2}$. This study is depending on integration data from well logs of 22 wells which provided from geology, geophysics, and petrophysics to identify and provide precise depict of the subsurface internal structure and the reservoir heterogeneity. Input data was used to build the structural model, sedimentary facies model, petrophysical properties (porosity, permeability, saturation, and N/G model, and finally to determine the reservoir volume. The lithological facies were simulated using the assigned value method. Moreover, Petrophysical properties (Porosity, permeability, oil saturation and net to gross) were constructed for each zone using the Sequential Gaussian Simulation method to guide the distribution of petrophysical properties of Es1 formation, block Nv32. Statistical analysis of the porosity, permeability, oil saturation and N/G model present that the porosity occurrence distribution is mainly concern between $0.2 \%-36.39 \%$ of block Nv32 with an average porosity value of $17.5 \%$, permeability between $0.017 \mathrm{mD}$ to $974.8 \mathrm{mD}$, having an average permeability of $59.44 \mathrm{mD}$, oil saturation between 0.00 to 0.95 having an average value of 0.22 , and N/G is mainly concentrated between 0.01 to 1.00 within an average value of 0.61 . This research has indicated the reliability of the three-dimensional model technique as a suitable tool to provide a suffi- 
cient understanding of petrophysical distribution. The south-western and north-western indicate that oilfield is very promising an exploratory well should be drilled to find out the thickness and size of the reservoir.

\section{Keywords}

3D Reservoir Geological Model, Es1 Formation, Block Nv32, Structural Model, Petrophysical Model

\section{Introduction}

When the oil has been discovered in a field, many studies will be required to evaluate and comprehend the reservoir heterogeneity, define the extent of the reservoir in the three-dimensional, evaluating the fluid volumetric in the reservoir and identify the suitable method to increase the reservoir fluid recovery. Generally, reservoir characteristics such as lithofacies heterogeneities, porosity, and permeability spatial variation control the reservoir performance, and development plans [1]. The 3D reservoir model represents the reservoir properties, thus building a static reservoir involve to accomplish four tasks which care out by specialists in multiple disciplines, these stages are Structural modeling, Stratigraphic modeling, Lithological modeling, and Petrophysical modeling. Typically, models are not exactly representing the reality, however, merely a computer-aided used to illustrate the property distribution of the reservoir characteristics to assist in the forecast of the reservoir forthcoming result. The reservoir model is an essential tool to identify the appropriate, safest drilling, completion, and recovery selection for the reservoir, and for the field development plane for that reservoir as well as [2]. This research aims to characterize and carry out 3D static modeling of Es1 formation, block Nv32 to make economic management decisions aimed towards the profitability of an oil company by reducing the capital investment by providing encouragement and confidence to the oil investment with the following objectives: Correlate the reservoir across the 22 wells, delineate the hydrocarbon bearing reservoir map out major faults within the field, compute the petrophysical parameters such as porosity, permeability net-to-gross ratio and saturation using the deterministic approach.

\section{Study Area}

Block Nv32 is located in the west of the Shenvsi oilfield (Dagan oilfield) in the south of Cangzhou City, Hebei province and its structure locate in between Cangxian and Kongdian structures. Due to the complex structure and fault development of the Shenvsi Oilfield, there are many blocks in the oil field. Moreover, block Nv32 mainly contains sandstone and carbonate rocks, sandstone with lithic argillaceous sandstone, feldspathic lithic sandstone, and a small amount of mixed sandstone. The structural area of the sand-oil top structure is $2.0 \mathrm{~km}^{2}$, the structural width is $100 \mathrm{~m}$, the proven oil-bearing area is $1.4 \mathrm{~km}^{2}$, and the petroleum geological reserves are $225 \times 10^{4}$ t. Figure 1 illustrates the location map of block Nv32. 


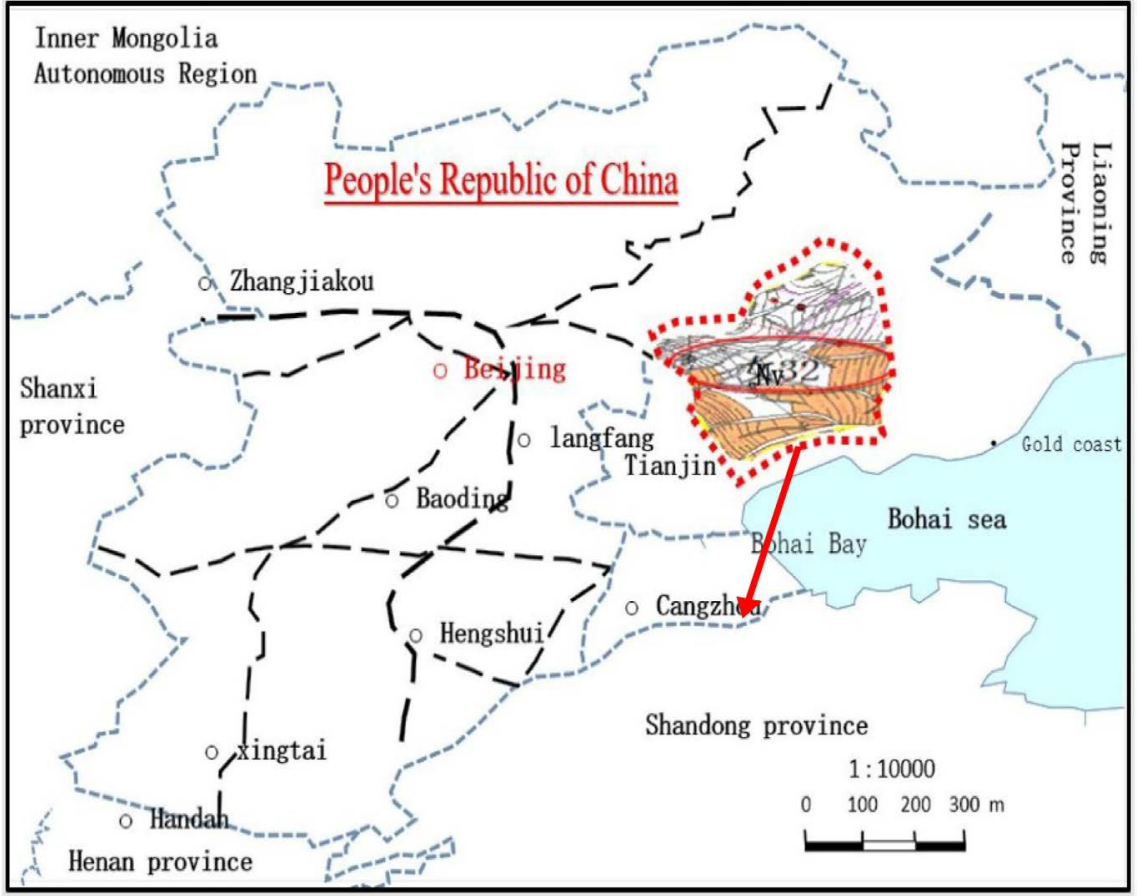

Figure 1. Map location of Es1 formation, block Nv32.

\section{Model Workflow}

The data used for this research were obtained from block Nv32 in China. These data include structural maps, fault lines, and well logs. Data were checked and organized properly, and then imported into Petrel software to build the $3 \mathrm{D}$ reservoir model. The workflow design used for the study and wide range of functional tools in the petrel software includes 3D visualization, well correlation, 3D mapping, and 3D grid design for geology simulation, well log upscaling, petrophysical modeling, data analysis, and volume calculation. Figure 2 illustrates the workflow model of Es1 formation.

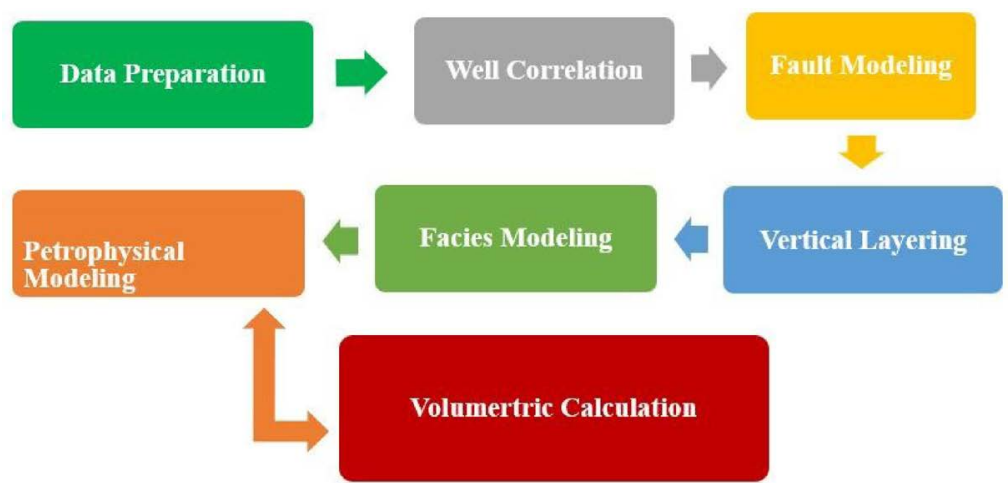

Figure 2. Workflow model of Es1 formation.

\section{Data Preparation}

Data preparation is the foremost stage for constructing a reservoir static model. Geomap3.6 and Petrel software are the chiefly software to construct this model. 
Based on Petrel's demand and area characteristics of Es1 formation, block Nv32. Three types of data were required to construct this reservoir static model which can be concluded as: well path data, structure data, and property data. Well path data to describe the pathway of wells across, while structure data is used to create a 3D grid, which includes individual layers data and fault data, on the other hand; Property data is used to generate property model by applying numerical analysis calculation to the data by property definition [3].

\section{Well Correlation}

Wells correlation has been performed to provide clear depict about the reservoir geological characteristic such as thickness change within Es1 formation units block Nv32, and the change of petrophysical properties such as a change in (Porosity, permeability, oil saturation, and N/G) of different units in Es1 formation. In accordance with data input into Petrel software, the correlation section for twenty-two well was performed. The sequence was subdivided into a lithological unit namely Shale, Sandstone, Limestone according to the sand characteristics of Es1 formation, Nv32 block. The correlating process of Es1 formation wells was made by using different logs such as Spontaneous potential (SP), Caliper (CAL) and Acoustic impedance (AC) logs to perform the well to well correlation. After data were inputted into Petrel software, the correlation section of Es1 formation was performed. Figure 3 illustrates the vertical and horizontal variations in the thickness of Es1 formation and the variations in petrophysical properties as well.

\section{Structural Modeling}

Structural modeling in Petrel is subdivided into three operations which can be included as follows: Fault modeling, Pillar gridding, and vertical layering. All the mentioned processes were performed sequentially to form a single data model [4]. A structure contour map is an essential tool for interpretation three-dimensional because it provides obvious depictions for the complete three-dimensional form of map horizon. Three-dimensional were constructed a base on the well top for all wells of Es1 formation, block Nv32. Figure 4 illustrates the 2D map of the Es1 formation top horizon.

\subsection{Fault Model}

The fault model was the primary step for constructing a structure model with petrel workflow tools. Es1 formation mainly consists of fifteen faults. Fault type in bock Nv32 is normal and reverse fault. This fault model has used the fault polygon which Petrel software provides to each type of vertical fault, diagonal fault, curve fault, and various geometry structure fault according to the fault polygon. The initial surface was established by applying fault polygon with various stratification planes, then fault section was corrected by adjusting the fault section, uses breakpoint data obtained by single well correlation, correct the position and shape of fault revision fault and shape, make it convenient and anastomosing. Figure 5 illustrates the fault model of Es1 formation, block Nv32. 

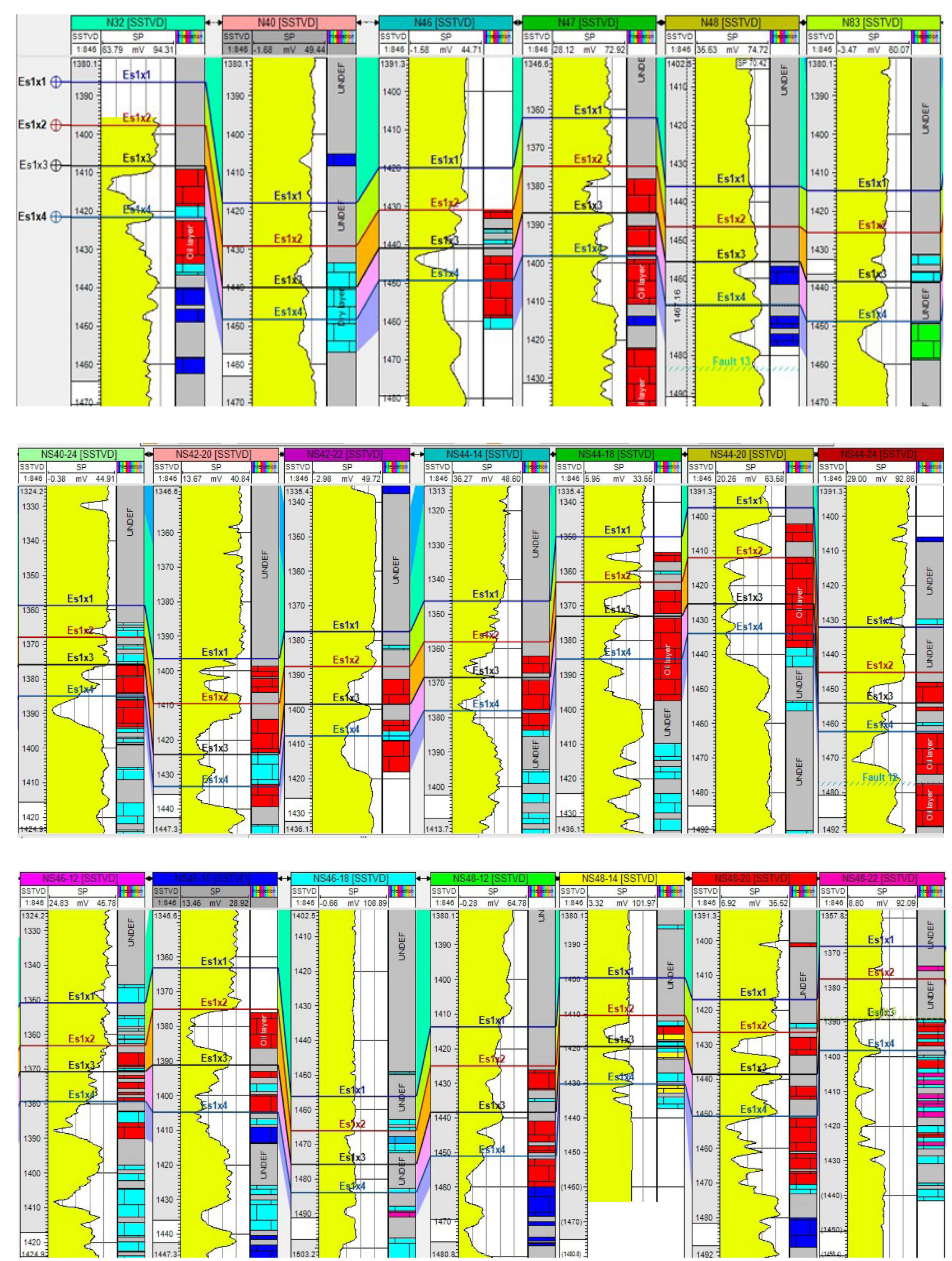

Figure 3. Well correlation of Es1 formation, block Nv32. 


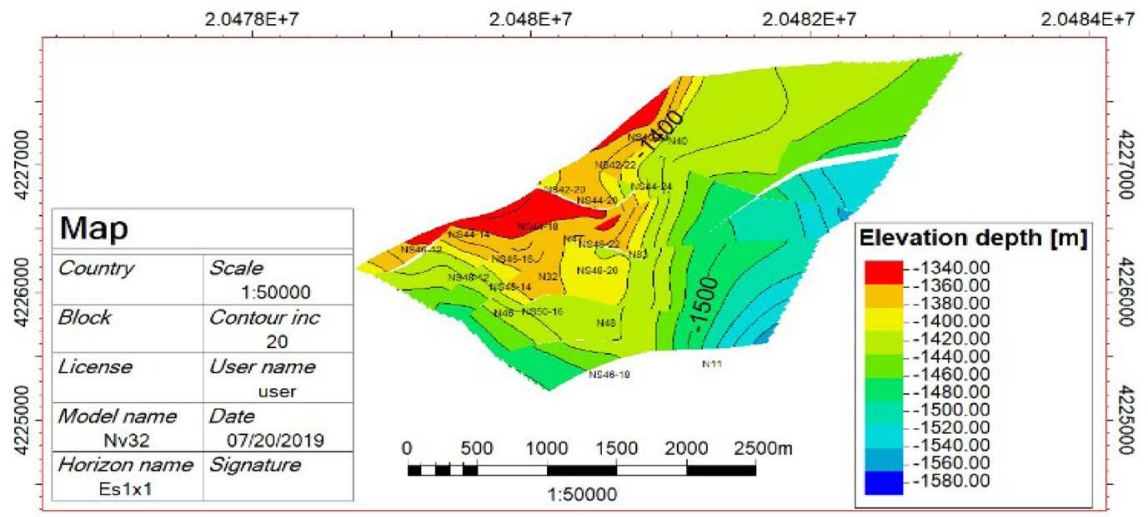

Figure 4. 2D map of Es1 formation top horizon.

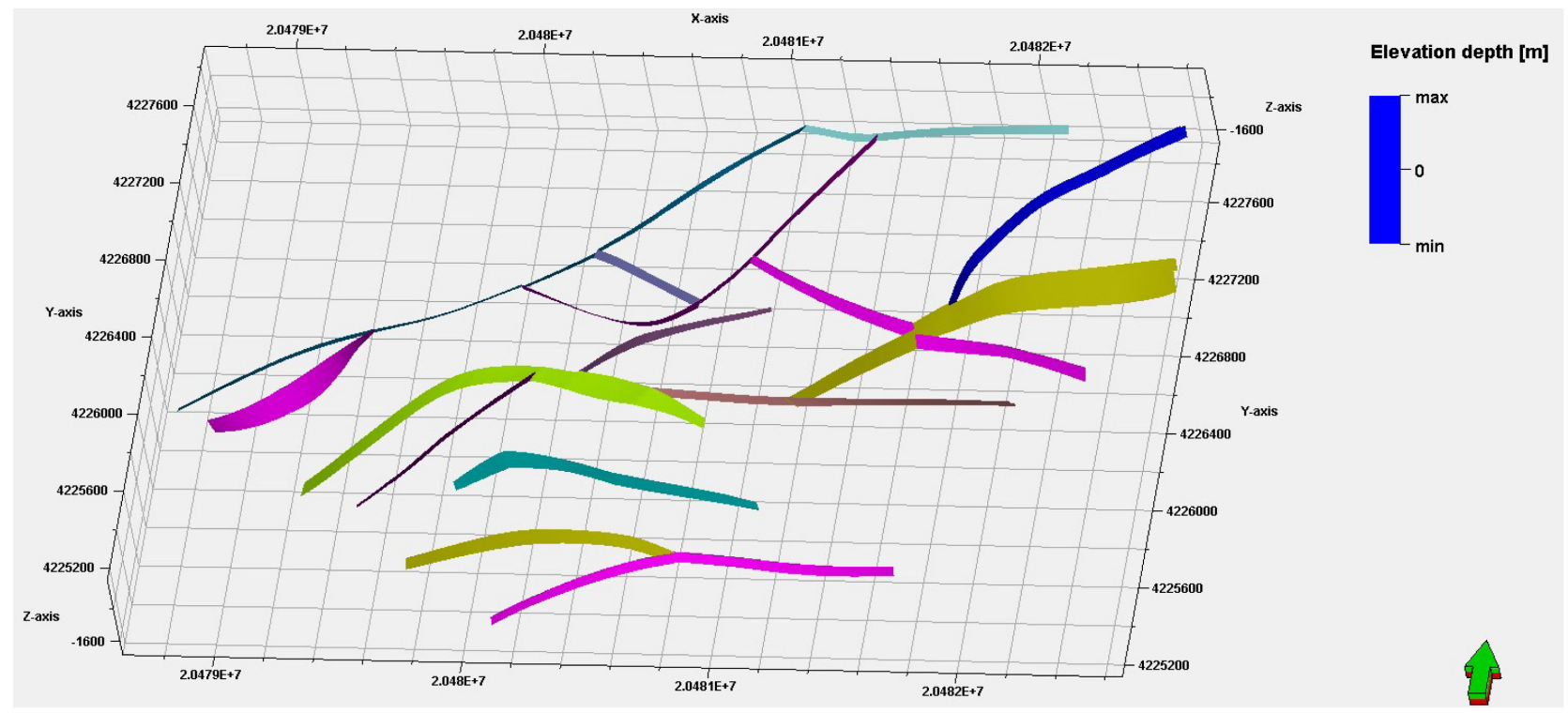

Figure 5. Fault model of Es1 formation, block Nv32.

\subsection{The Layering of Geological Model}

Identify the thickness and the directions of layers among the horizons of this $3 \mathrm{D}$ grid was the final step to construct the structure framework. Moreover, Modern geology required an accurate illustration of layered volumes. Recently, the three-dimensional geological model is the most effective method for constructing the geological model at depth [5]. Each unit in Es1 formation, block Nv32 had been divided into many layers based on the lithological, Petrophysical properties.Es $1 \times 1$ and Es $1 \times 2$ consist of 11 layers, however, Es $1 \times 3$ and Es $1 \times 4$ consist of 10layers which based on the petrophysical properties. Figure 6 illustrates the layering of Es1 formation, block Nv32.

\subsection{Facies Modeling}

Facies modeling is discrete throughout the model grid. Facies model of Es1 Formation, block Nv32 has constructed the base on the outcome result of the microfacies interpretation of sedimentary environments as obtained from logs. 
The Es1 formation primarily consists of three types of lithology which are shale, limestone, and sandstone with a proportion of $32.42 \%, 29.49 \%$, and $38.09 \%$ respectively. However, limestone is the predominated reservoir rock in block Nv32. The assigned value method was applied to simulate the sand bodies in Es1 formation. Figures 7-10 illustrate the facies model for each zone of Es1 formation, block Nv32.

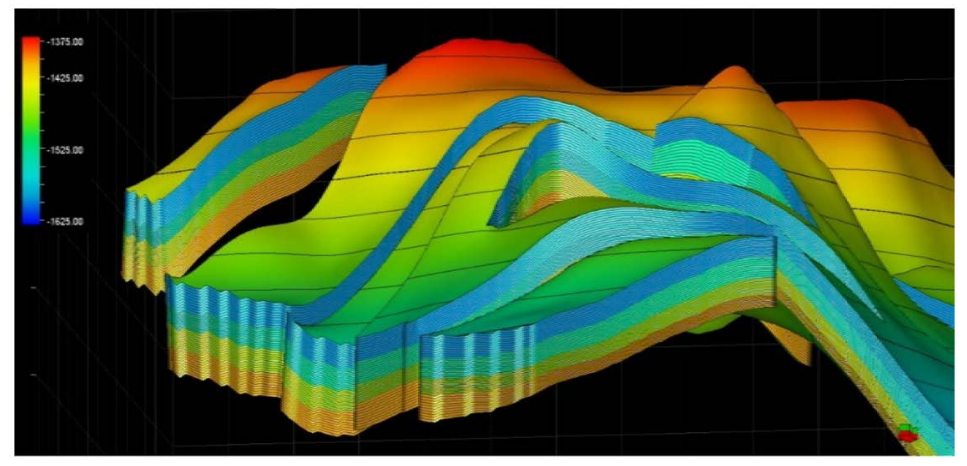

Figure 6. Layering of Es1 formation, block Nv32.

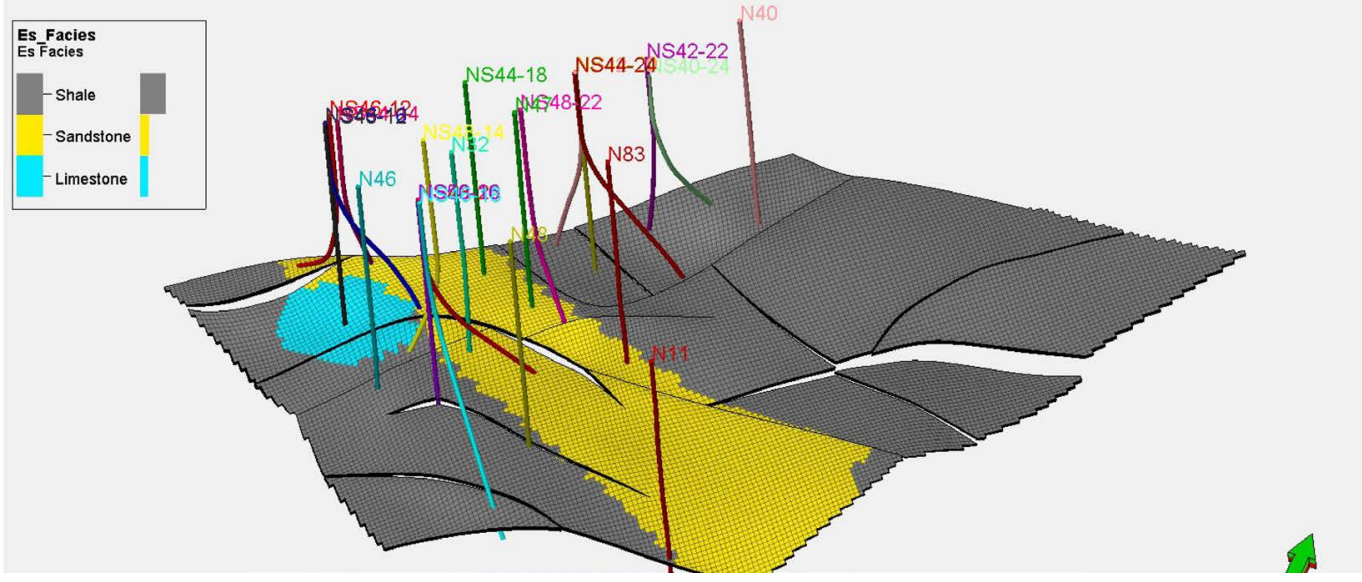

Figure 7. Facies model of Es $1 \times 1$.

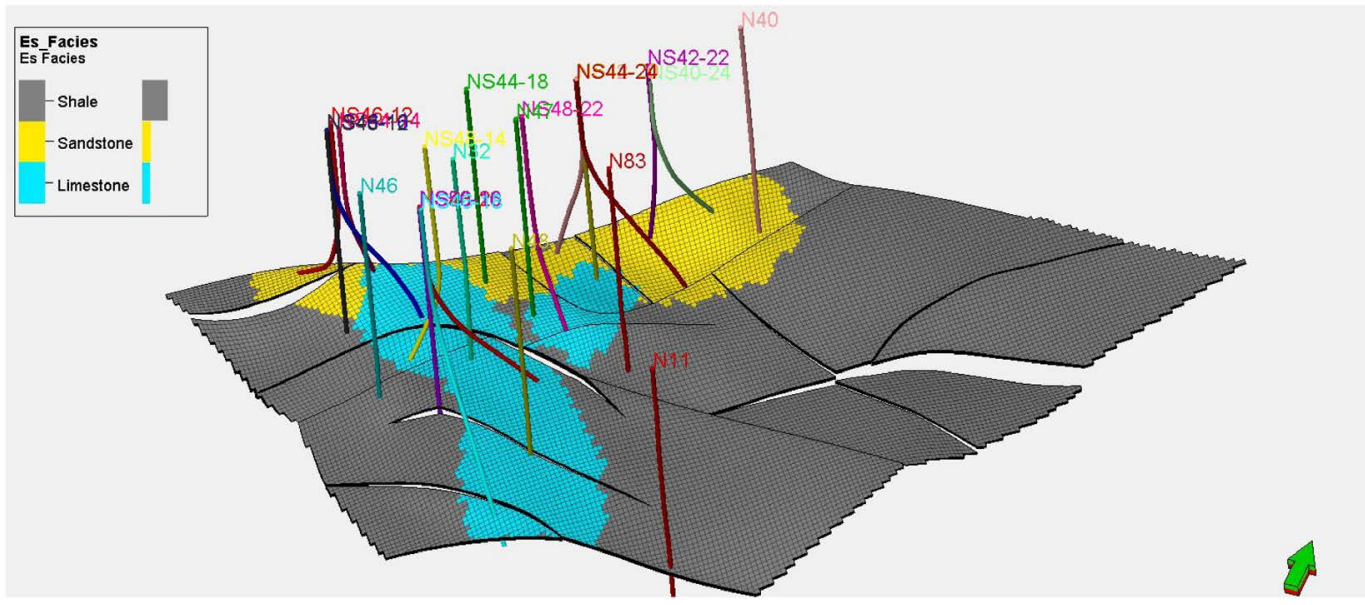

Figure 8. Facies model of Es $1 \times 2$. 


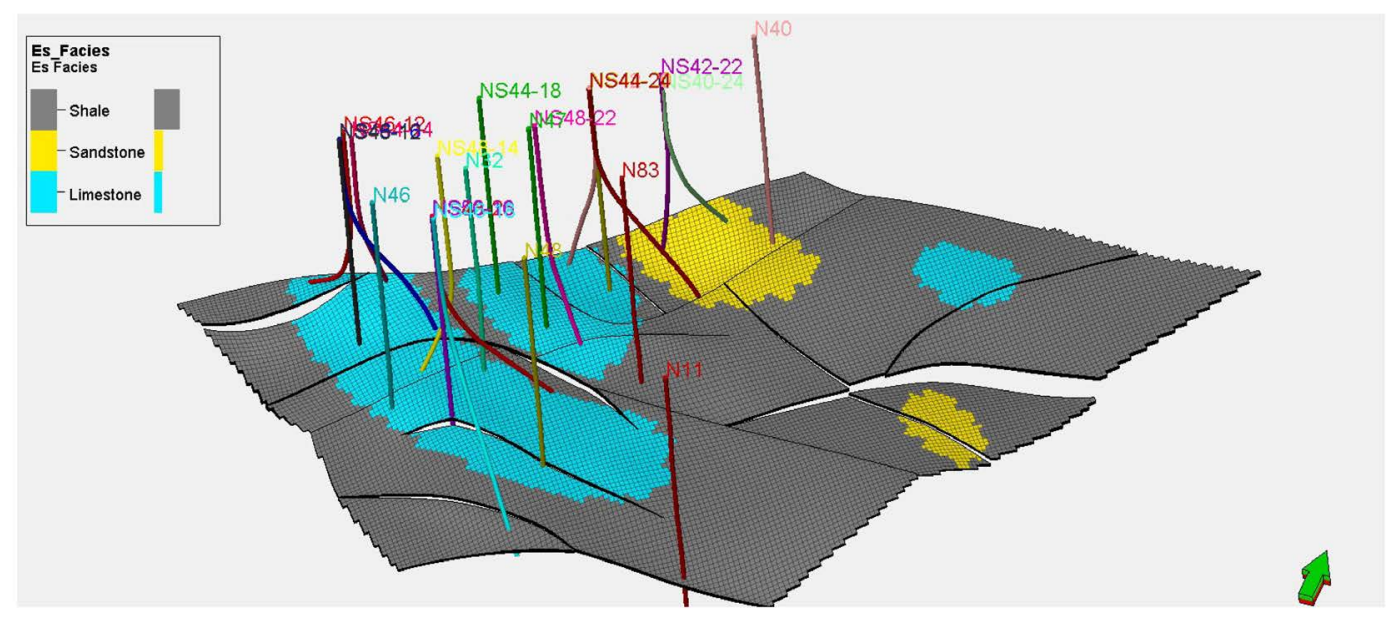

Figure 9. Facies model of Es1 $\times 3$.

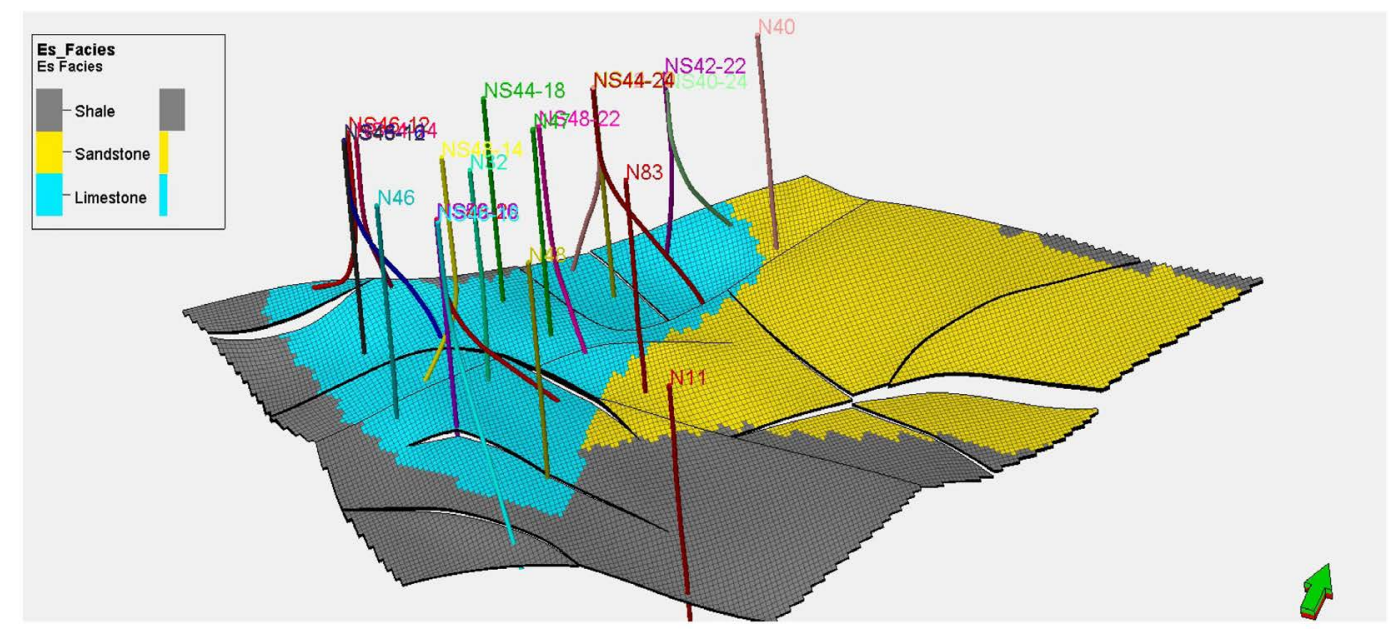

Figure 10. Facies model of Es1 $\times 4$.

\subsection{Petrophysical Modeling}

Petrophysical property modeling is known as the process of distributing reservoir properties into the geological grid. This is performed individually for each reservoir zone of the geological grid [6].

\subsection{Porosity Model}

Evaluate oil capacity in the oil reservoir is achieved by determining its porosity. The porosity model of Es1 formation was built based on the outcome result that has been determined from porosity which was obtained from the petrophysical interpretation of block Nv32 wells. In this model, the porosity model was constructed for each unit of Es1 formation, block Nv32. The arithmetic average method was applied to scale up the well logs. Sequential Gaussian Simulation method was used to distribute the porosity in the model. The porosity occurrence distribution is a concern between $0.2 \%-36.39 \%$ of Es1 formation, block Nv32 with an average porosity value of $17.5 \%$. Table 1 presents the outcome result which indicates that Es1 formation, block Nv32 is a good reservoir. Figure 
11 represents the porosity histogram of Es1 formation which indicates that the porosity of Es1 formation is a range between $0.2-0.36$. Porosity reduces in some parts because of the clay contents, and the heterogonies. Figures 12-15 represent the porosity model of Es1 formation, block Nv32.

Table 1. Porosity model result.

\begin{tabular}{cc}
\hline Type of Data & Continuous (\%) \\
\hline Min & 0.2 \\
Max & 36.39 \\
Mean & 17.5 \\
Std.dev. & 8.54 \\
\hline
\end{tabular}

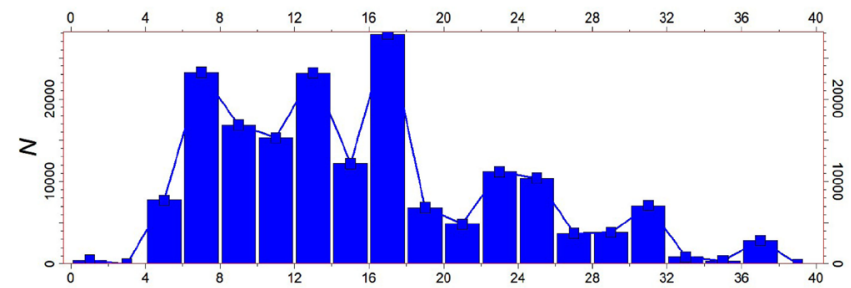

Figure 11. Porosity histogram of Es1 formation.

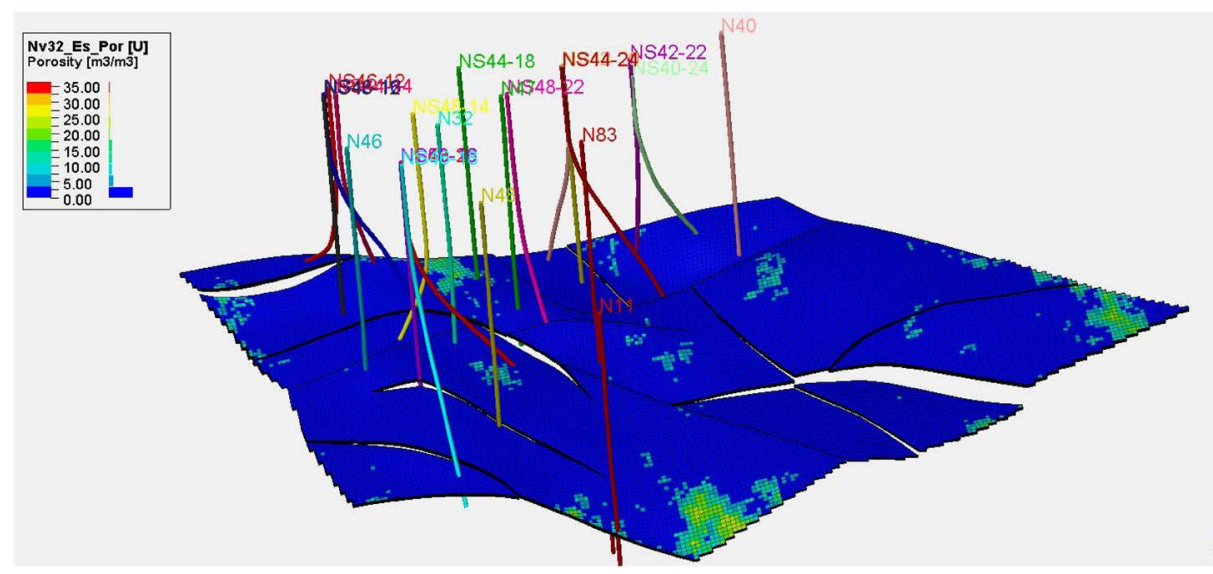

Figure 12 . Porosity model zone Es1 $\times 1$, block Nv32.

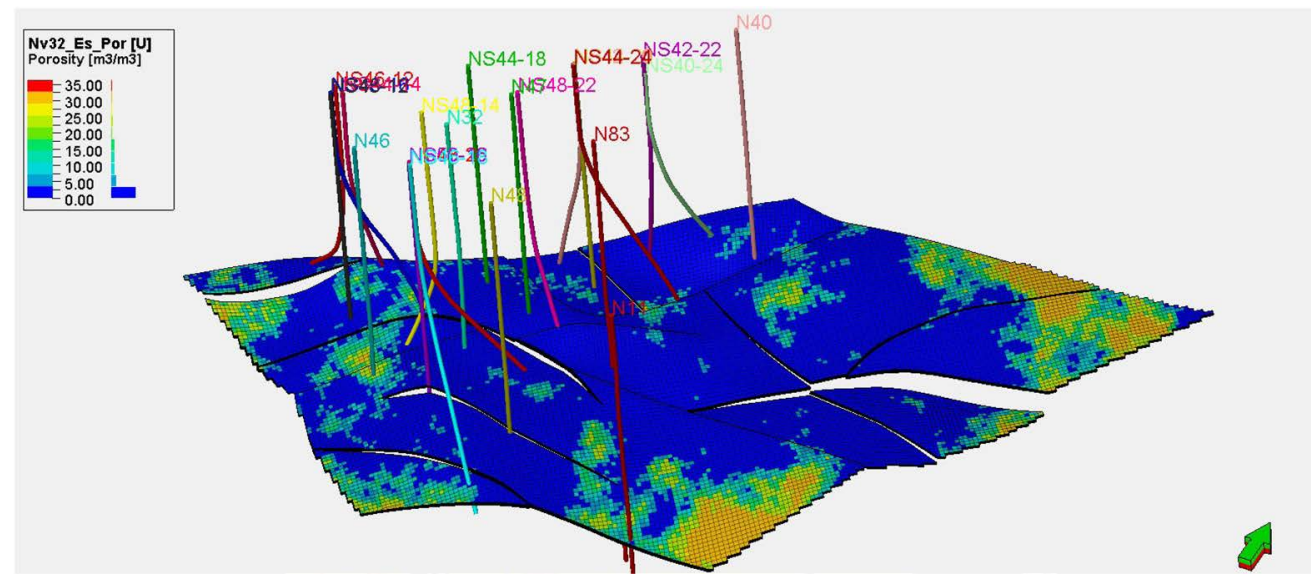

Figure 13 . Porosity model zone Es1 $\times 2$, block Nv32. 


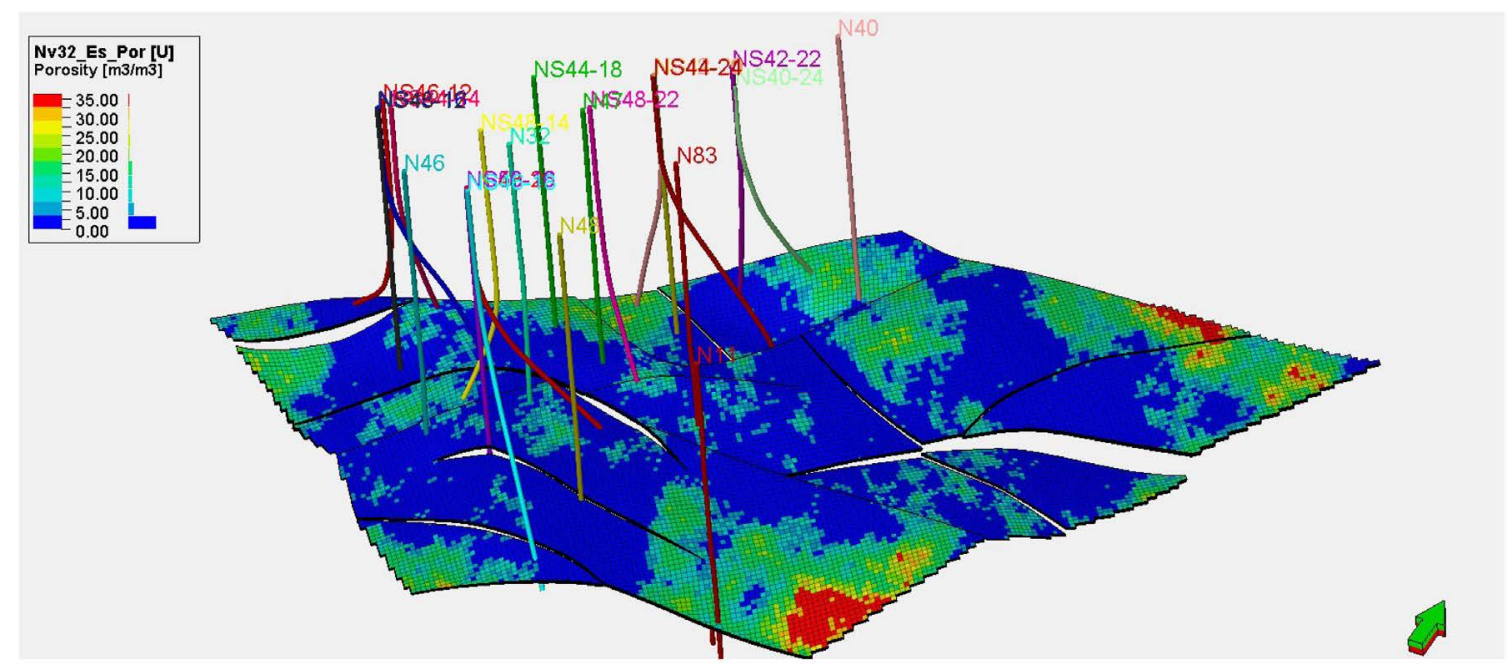

Figure 14. Porosity model zone Es1 $\times 3$, block Nv32.

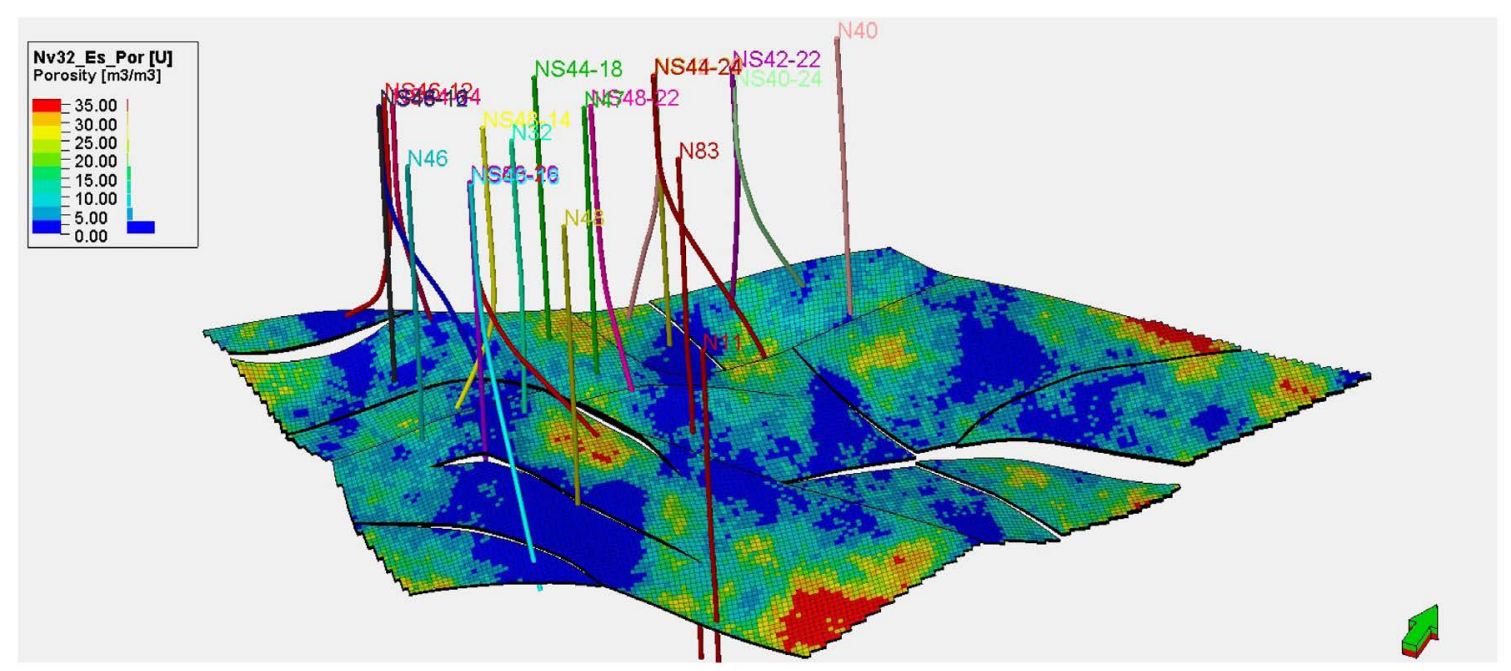

Figure 15. Porosity model zone Es1 $\times 4$, block Nv32.

\subsection{Permeability Model}

Permeability is an essential parameter in the reservoir rock. Its measure of the ease with which a fluid flows through the connecting pore space of the reservoir rock. The reservoir rock permeability is a vital property to determine the orientation movement and flow rate of the reservoir fluid in the formation. In this model, the permeability model was based on the permeability log generated [7]. The harmonic average method was applied to scale up the well logs. Furthermore, Sequential Gaussian Simulation was used as the statistical method to create the permeability model. The permeability model shows that the permeability of Es1 formation, block Nv32 is concentrated between $0.017 \mathrm{mD}$ to $974.8 \mathrm{mD}$, having an average permeability of $59.44 \mathrm{mD}$. The outcome value is indicated that Es 1 formation has good permeability, thus Es1 formation is considered as a good reservoir rock. Figures 16-19 represent the permeability model of Es1 formation, block Nv32. 


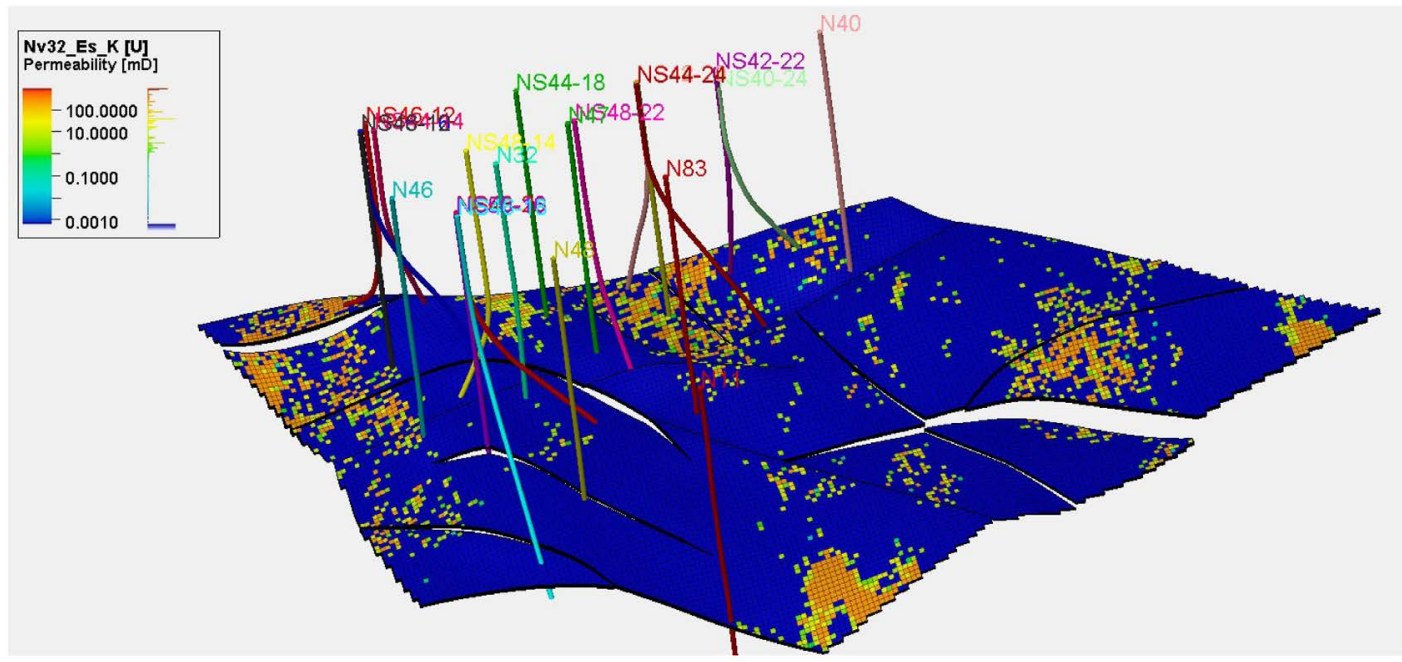

Figure 16 . Permeability model Zone Es $1 \times 1$.

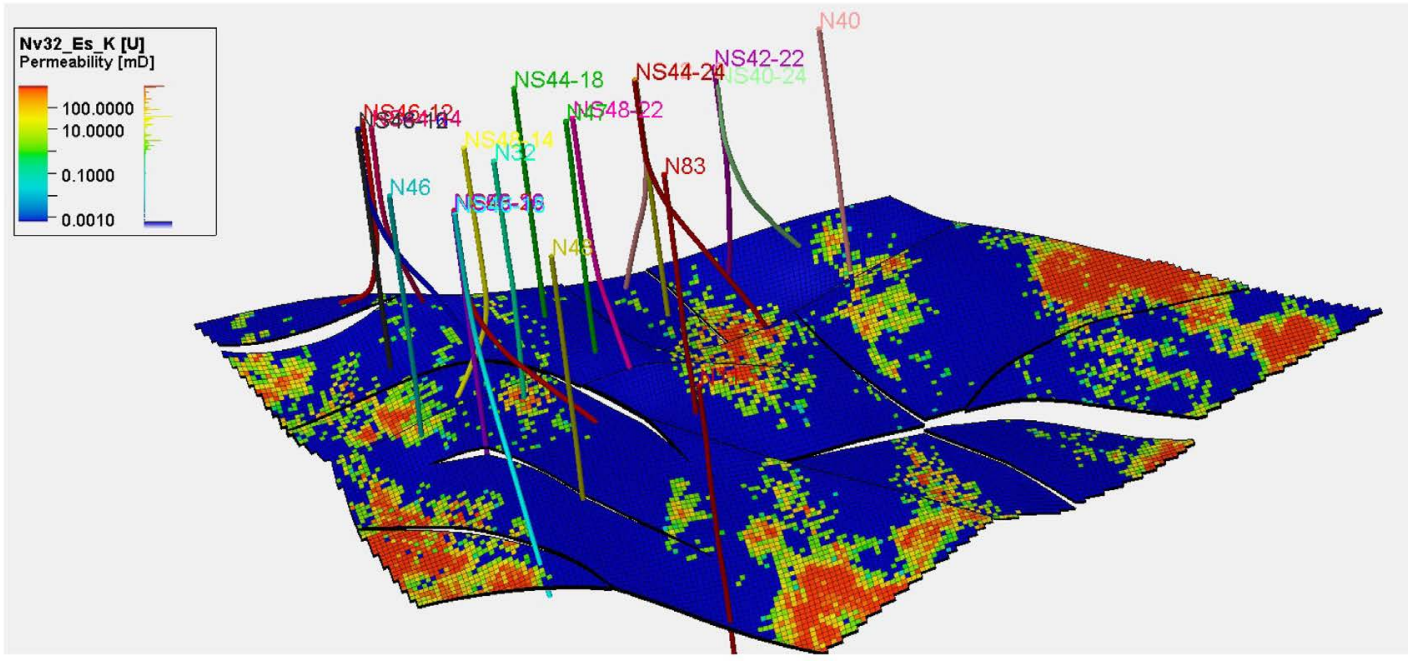

Figure 17. Permeability model Zone Es1 $\times 2$.

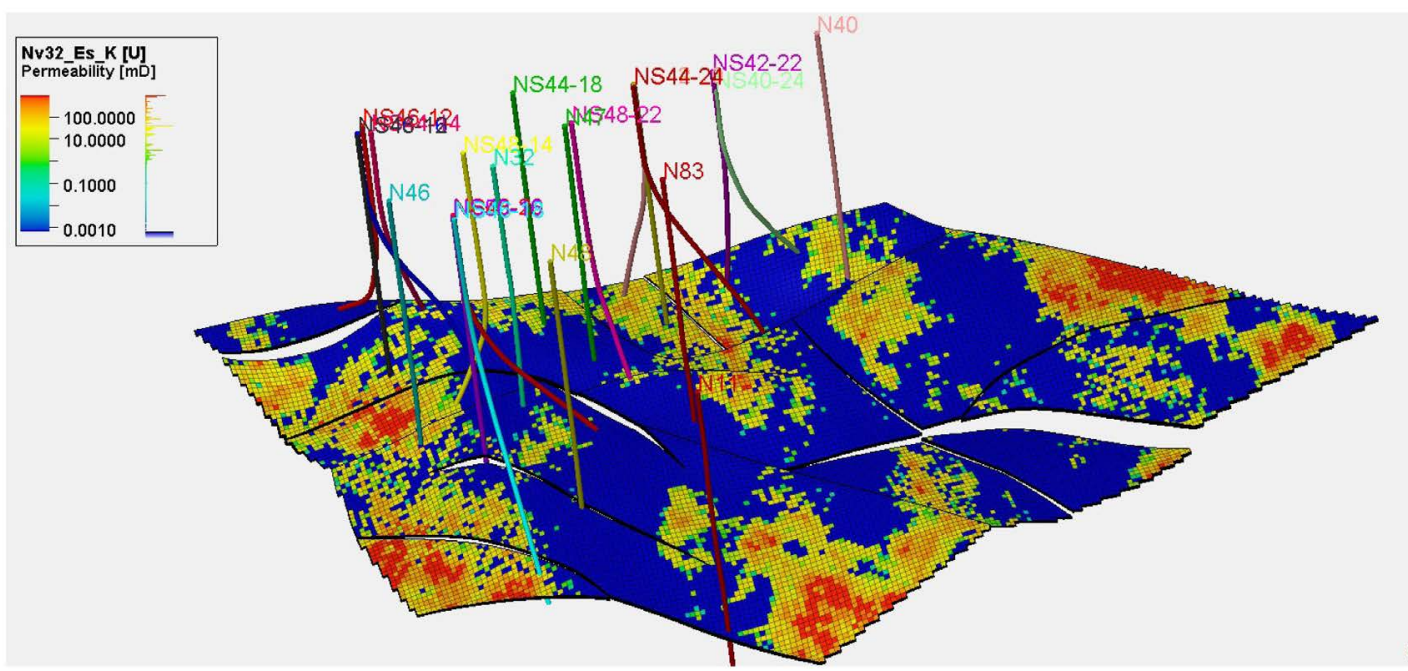

Figure 18 . Permeability model Zone Es1 $\times 3$. 


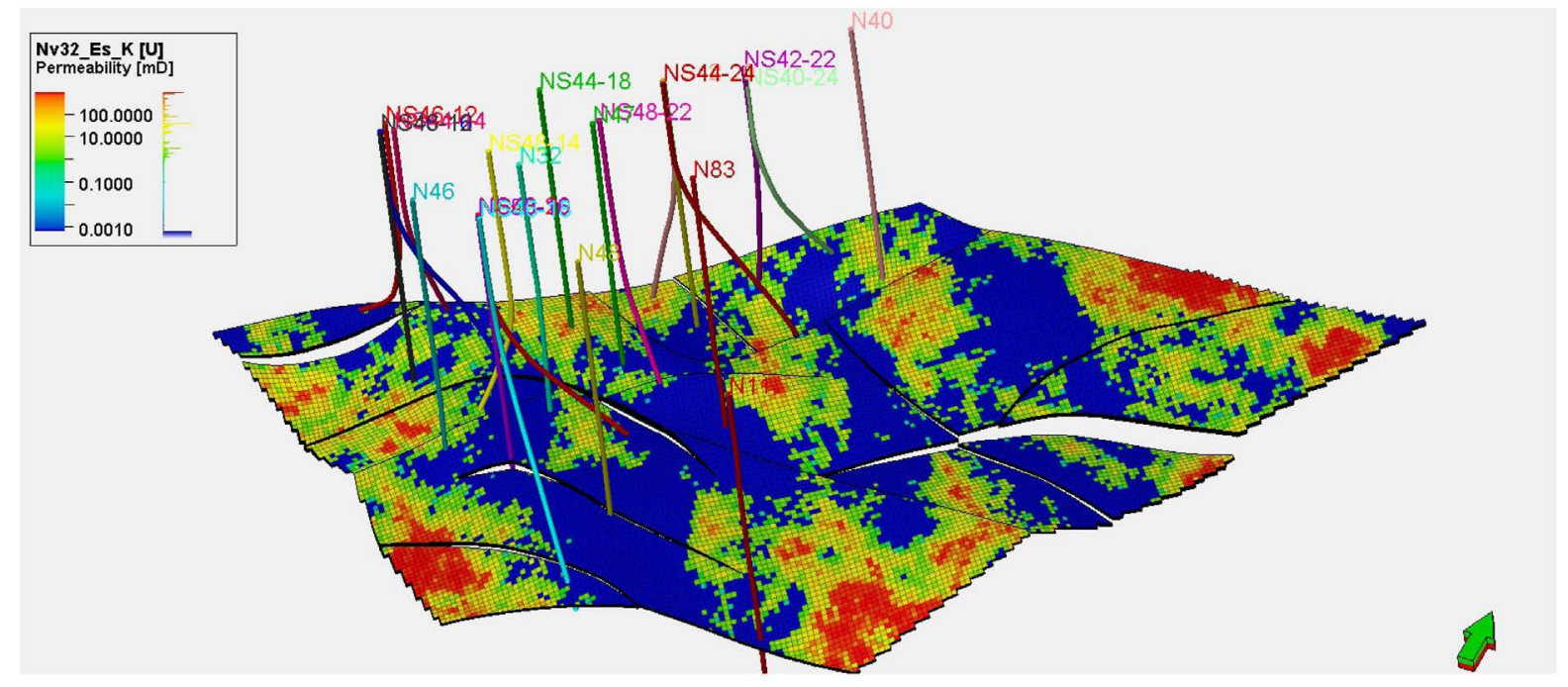

Figure 19. Permeability model Zone Es1 $\times 4$.

\subsection{Oil Saturation Model}

The saturation distribution model is known as the percentage between oil, water, and gas in the reservoir pore space. Saturation is an essential tool to identify a high prospective water area [8]. In the absence of core data, a deterministic of oil saturation was achieved from petrophysical interpretation. Sequential Gaussian Simulation was used to construct the oil saturation model of Es1 formation, block Nv32. Figures 20-23 show a 3D perspective view of oil saturation. The saturation model shows that the saturation of Es1 formation is mainly concentrated between $0.00 \%$ to $95.9 \%$, having an average saturation of $22.2 \%$. Es $1 \times 1$ zone reveals that the oil saturation is relatively concentrated in northwestern and southeastern. However, oil saturation in Es $1 \times 2$ and Es $1 \times 3$ are concentrated in the west to southwestern. Moreover, Es1 $\times 4$ is highly concentrated in the west to southwestern, also relatively oil saturation is concentrated in the north part.

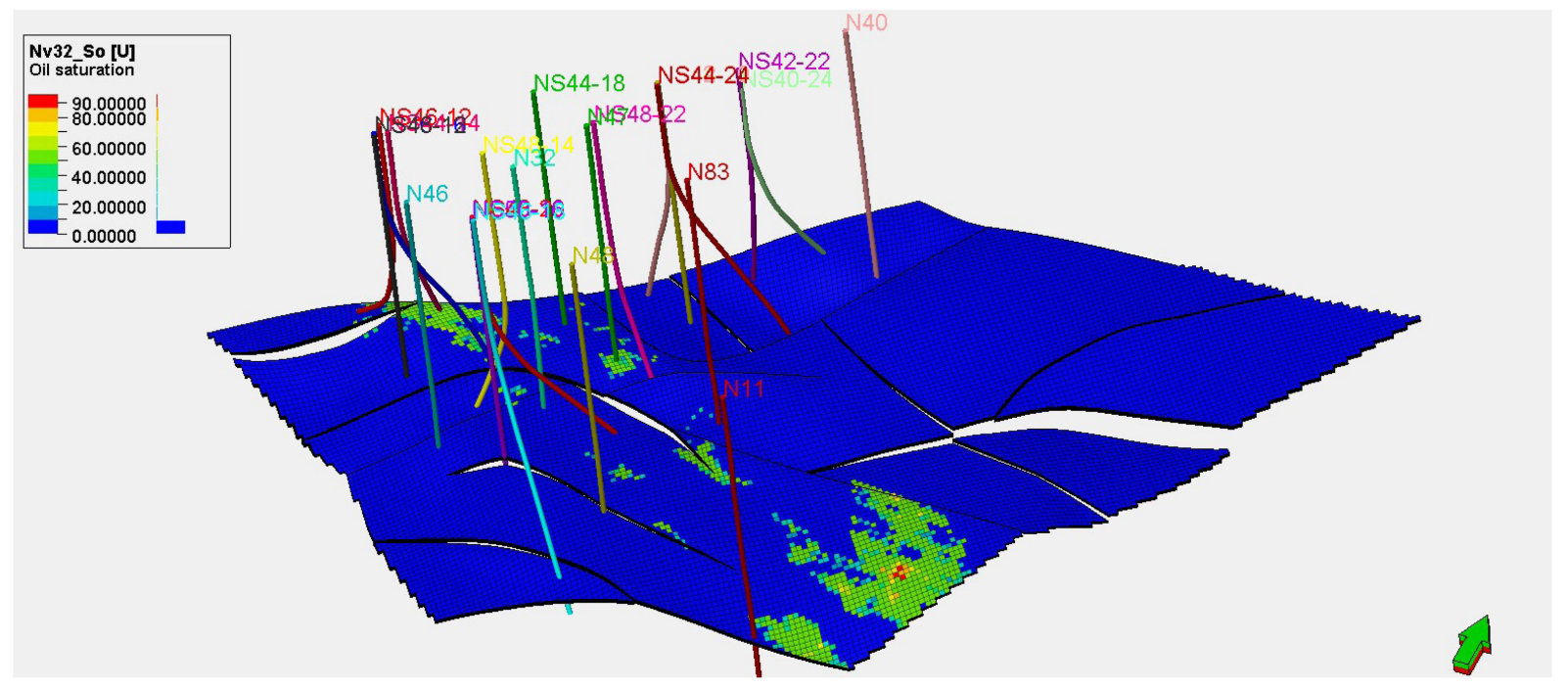

Figure 20. Oil-Saturation mode zone Es1 $\times 1$. 


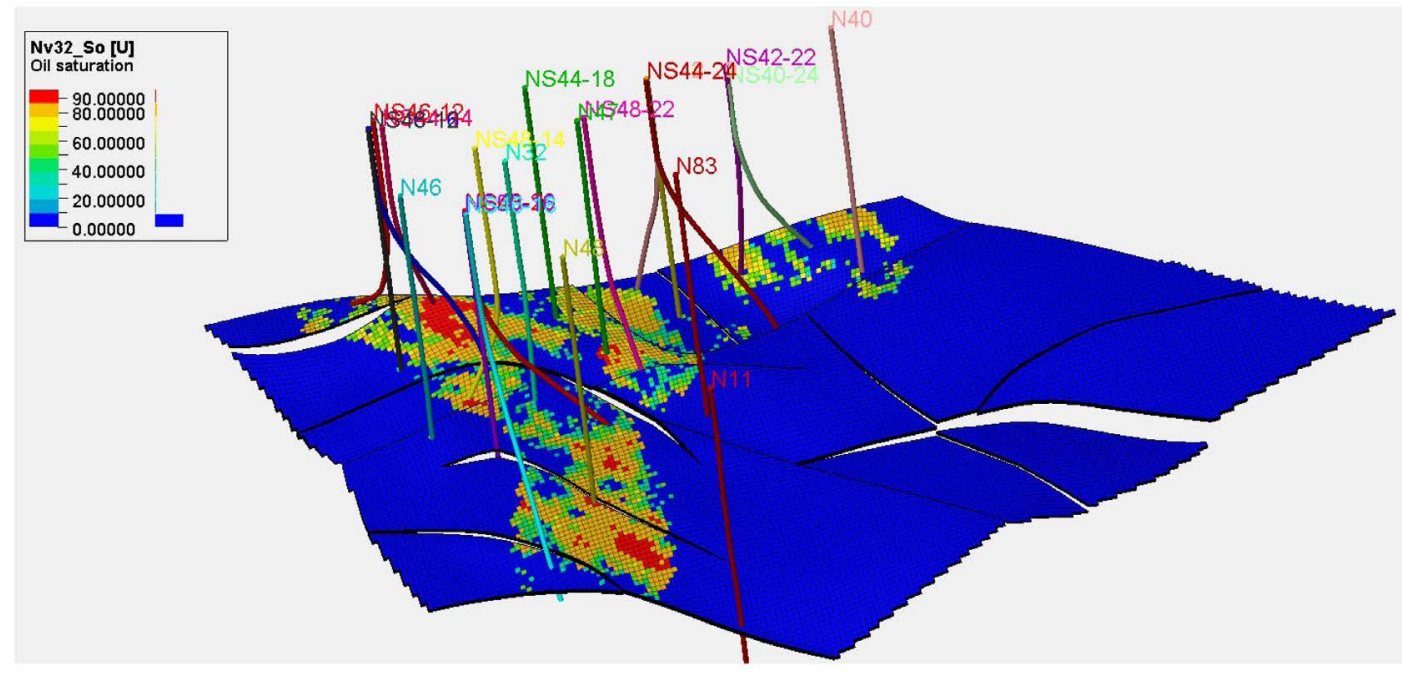

Figure 21. Oil-Saturation mode zone Es1 $\times 2$.

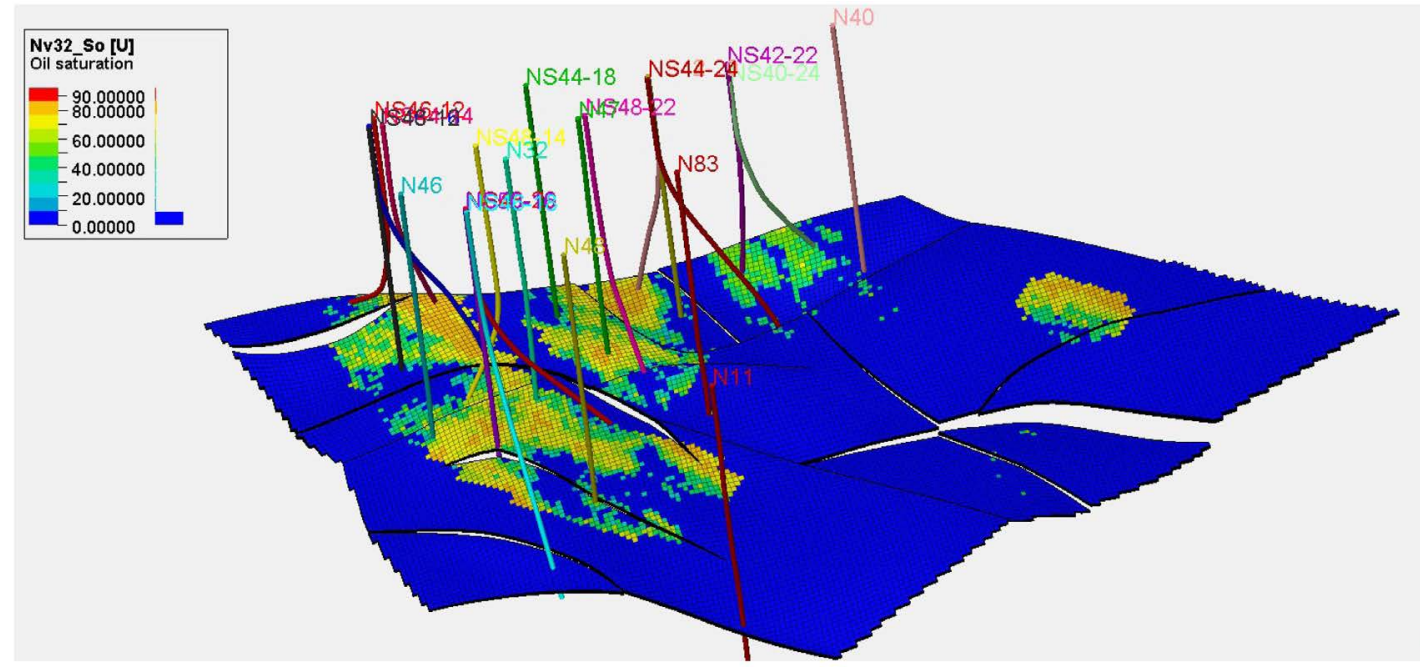

Figure 22. Oil-Saturation mode zone Es1 $\times 3$.

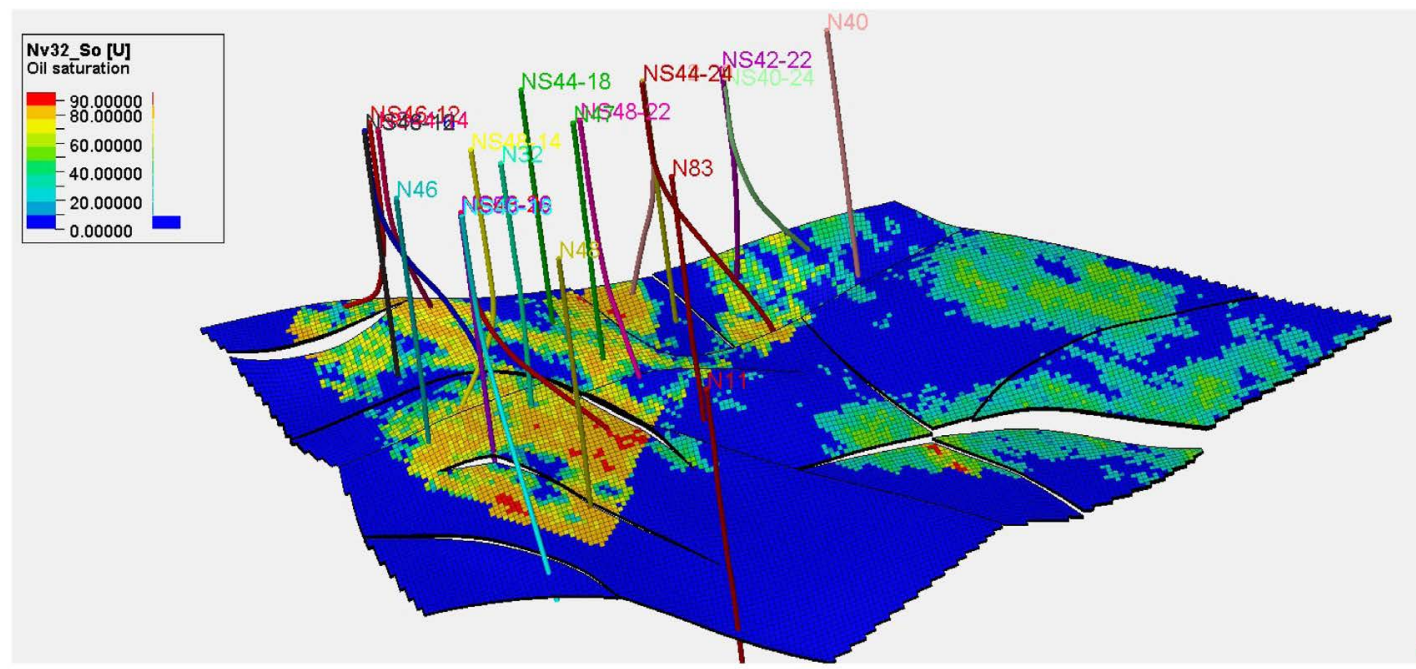

Figure 23. Oil-Saturation mode zone Es1 $\times 4$. 


\subsection{Net to Gross Model}

Net to Gross ratio is used to eliminate non-productive reservoir rock unit if exist. Moreover, limestone is the predominant reservoir rock of Es1 formation. Thus, Net to gross was set to unity for the volume calculation. The arithmetic average method was applied to scale up the well logs. Moreover, the Sequential Gaussian Simulation method was used to build the Net to Gross model of Es1 formation, block Nv32. Net to Gross model shows that the N/G of Es1 formation is primarily concentrated between 0.01 and 1.00 within an average value of 0.61 . Table 2 represents the outcome result of N/G. Figures 24-27 represent the Net to Gross model.

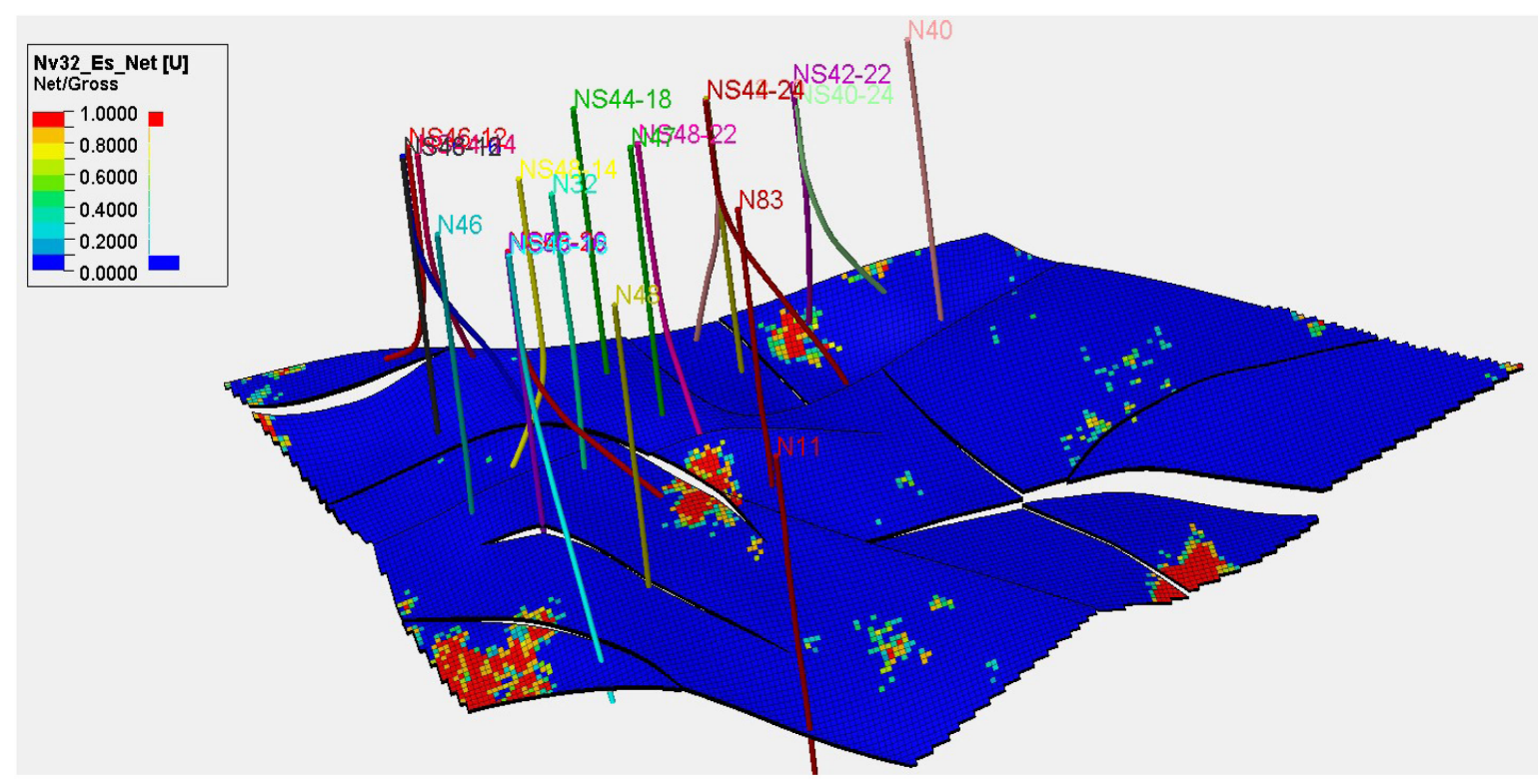

Figure 24. Net to gross model zone Es1 $\times 1$.

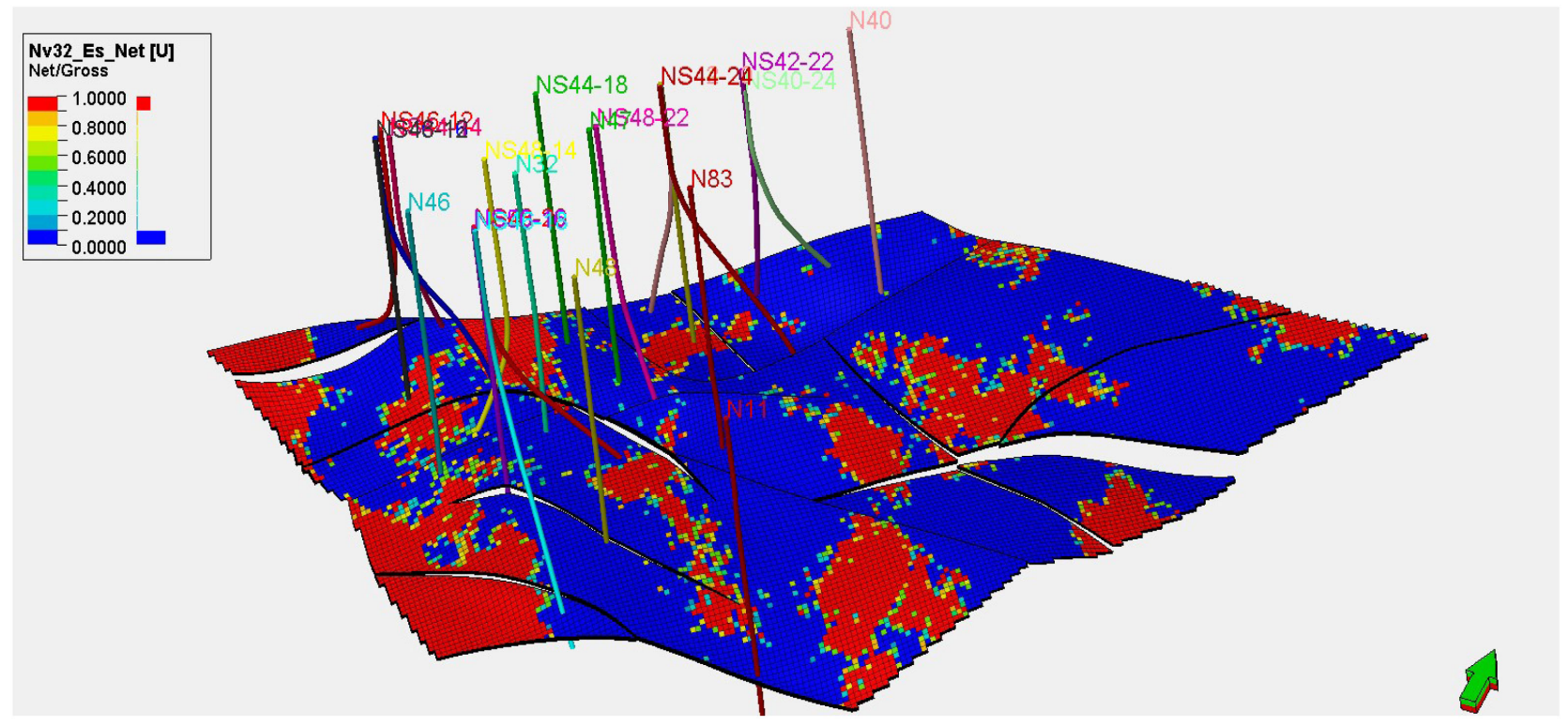

Figure 25. Net to gross model zone Es1 $\times 2$. 


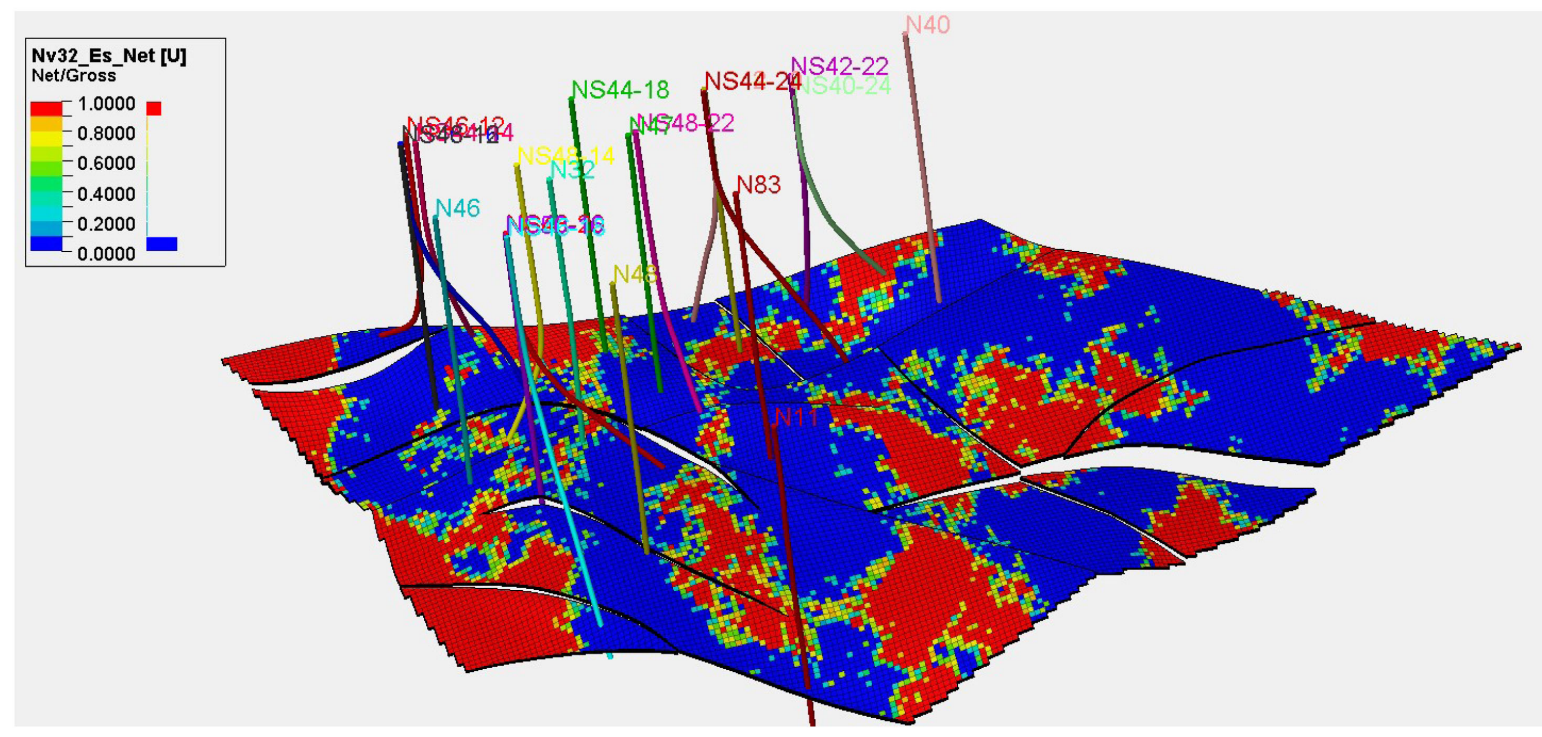

Figure 26. Net to gross model zone Es1 $\times 3$.

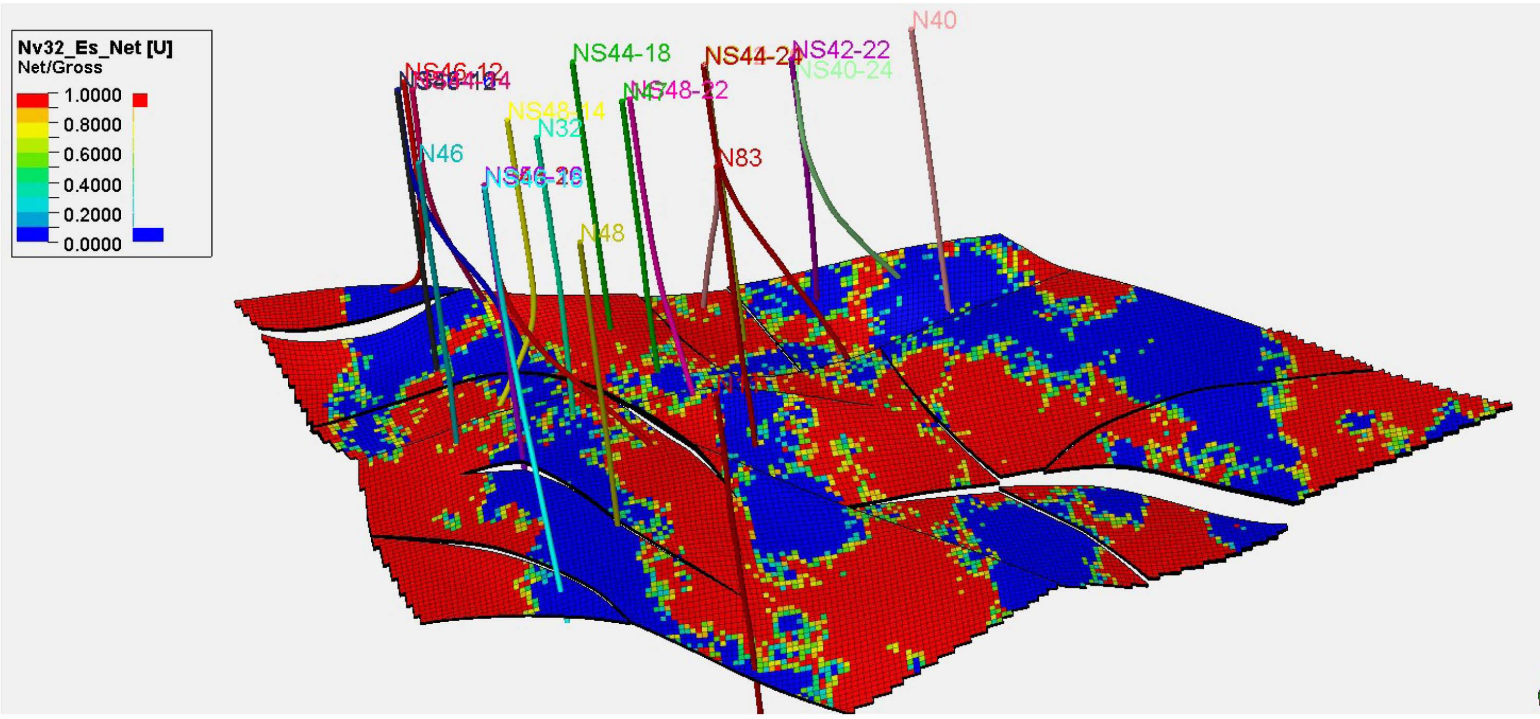

Figure 27. Net to gross model zone Es1 $\times 4$.

Table 2. Net to gross model result.

\begin{tabular}{cc}
\hline Type of Data & Continuous (\%) \\
\hline Min & 0.00 \\
Max & 1.00 \\
Mean & 0.613 \\
Std. Dev. & 0.449 \\
\hline
\end{tabular}

\section{Reservoir Volumetric}

Estimate the quantity of hydrocarbon in the reservoir is known as reservoir volumetric. Reservoir volumetric is an essential part of the geological model be- 
cause it provides the basis for oilfield exploration and development. Furthermore, reservoir volumetric can examine the reliability of the model [8]. In this model, various data were analyzed and bounded to create a three-dimensional geological model. The Es1 formation, block Nv32 was initially defined by its top formation and base formation, four main horizons, and 42 sub-layers. Petrophysical analysis of all properties and Oil-Water contact was determined. The oil formation factor which was obtained from the laboratory from the PVT analysis was used as $1.21 \mathrm{bbl} / \mathrm{STB}$ to calculate hydrocarbon volume initially in place in standard condition (14.7 Psi, $60 \mathrm{~F}$ ). Also, when the reservoir model of Es1 formation was completed, the structure model and property model were used to calculate oil reserve in term of Stock Tank Oil Initial in Place (STOIIP). The Es1 formation was estimated by applying the equation [9]-[17]. Table 3 shows the volumetric outcome result after modeling has been done.

$$
\text { STOIIP }=7758 \times A \times h \times \phi \times\left(1-S_{\mathrm{W}}\right) \times \frac{1}{B_{0}}
$$

Table 3. Volumetric calculation results.

\begin{tabular}{ccc}
\hline Zones & $\begin{array}{c}\text { Bulk Volume } \\
{\left[\times 10^{6} \mathrm{~m}^{3}\right]}\end{array}$ & $\begin{array}{c}\text { STOIIP (in oil) } \\
{\left[\times 10^{6} \mathrm{sm}^{3}\right]}\end{array}$ \\
\hline Es1 $\times 1$ & 43.894771 & 0.554368 \\
Es1 $\times 2$ & 36.879991 & 4.7069397 \\
Es1 $\times 3$ & 29.936135 & 4.7828403 \\
Es1 $\times 4$ & 27.843010 & 10.0377143 \\
Case & 138.553907 & 20.0819 \\
\hline
\end{tabular}

Table 3 indicates that oil in zone Es $1 \times 3$ and Es $1 \times 4$ is high and commercial to produce from these zones. Figure 28 and Figure 29 illustrate the oil-bearing zone for Es $1 \times 3$ and Es $1 \times 4$ which reveal a huge area of the oil-bearing zone for the last two zones.

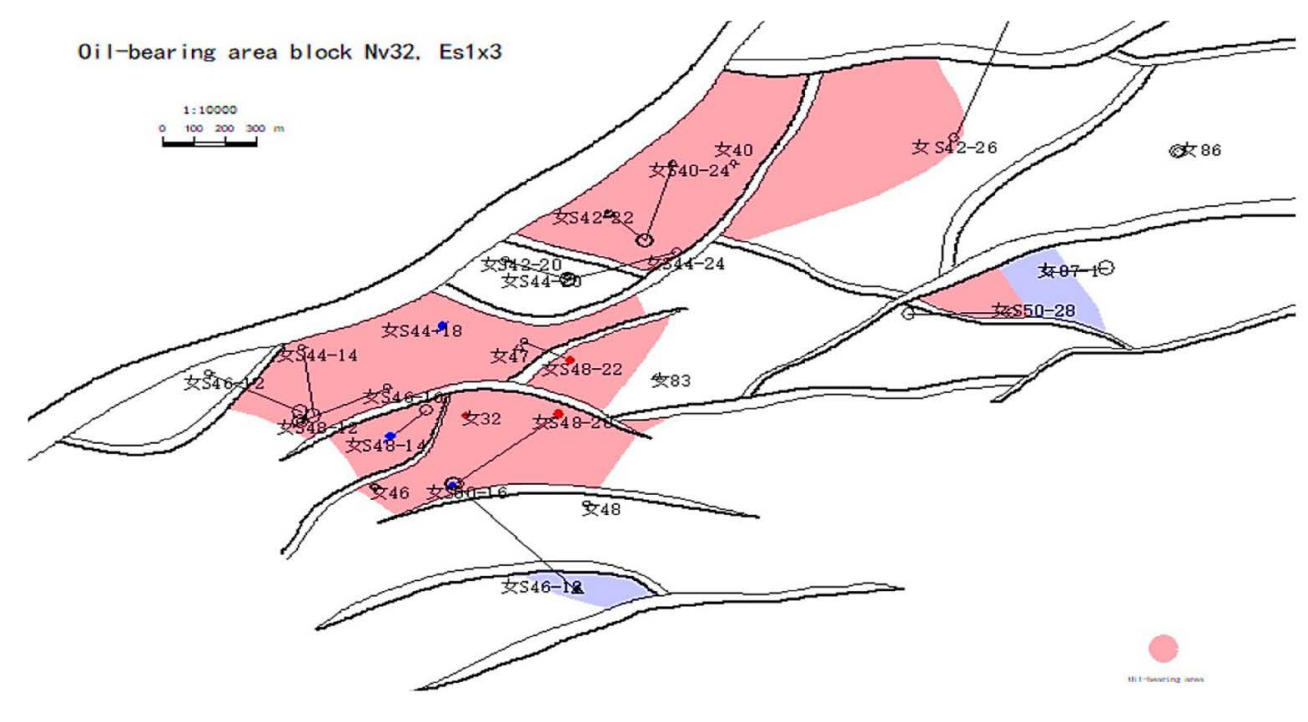


Figure 28. Oil-bearing area for zone Es1 $\times 3$.

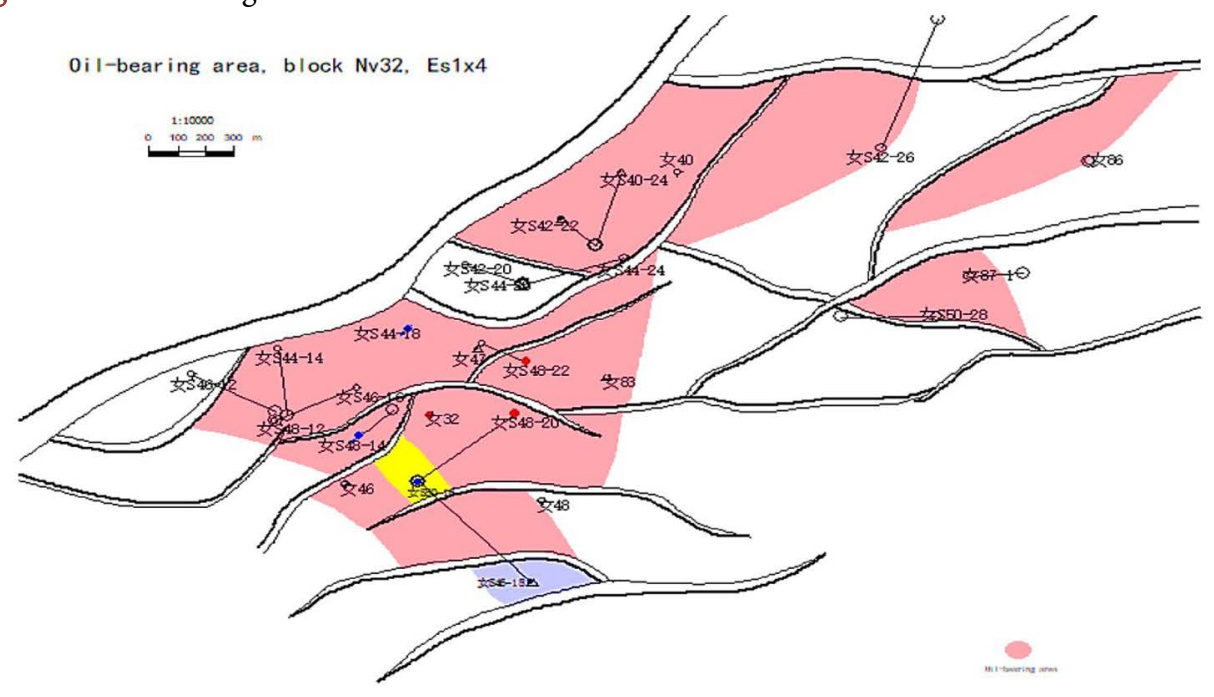

Figure 29. Oil-bearing area for zone Es1 $\times 4$.

\section{Conclusions}

The overall values such as porosity and permeability indicate that Es1 formation, block Nv32 is a good and promising oilfield, because of its good porosity and permeability values.

1) The structural model has been completed for Es1 formation, block Nv32. This model describes the structure trap characteristic, identify the distribution, geometry structure, reservoir attitude, and development of faults and fractures of Es1 formation, block Nv32.

2) Horizons were constructed for Es1 formation, block Nv32, and they are divided into 4 zones namely as Es $1 \times 1$, Es $1 \times 2$, Es $1 \times 3$, and Es $1 \times 4$. Based on the facies, petrophysical properties, layers were built for each zone. Es $1 \times 1$, Es $1 \times 2$ zones were divided into 11 layers. However, Es $1 \times 3$ and Es $1 \times 4$ were divided intol0layers, and this was based on the thickness and petrophysical properties.

3) Facies modeling for block Nv32 was built using the assigned value method. This model shows that Es1 formation consists of three types of lithology which are shale, limestone, and sandstone with a proportion of $32.42 \%, 29.49 \%$, and $38.09 \%$ respectively. However, limestone is the predominated rock in this reservoir.

4) The petrophysical model (porosity, permeability, oil saturation, and Net to Gross) of Es1 formation was built based on their values using the Sequential Gaussian Simulation method as a statistical method. Es $1 \times 3$ and Es $1 \times 4$ are the highest petrophysical properties in terms of porosity, permeability.

\section{Acknowledgements}

My deepest thanks and gratitude go to my parents, brothers, and professor Guan Zhenliang for their high support and motivation. I would like to convey my special thanks to Dr. Atif Zafar for his sincere advice and continuous support as 
well as constructive comments which helped me to think critically.

\section{Conflicts of Interest}

The authors declare no conflicts of interest regarding the publication of this paper.

\section{References}

[1] Jia, A., He, D. and Ji, C. (2012) Advances and Challenges of Reservoir Characterization: A Review of the Current State-of-the-Art. In: Earth Science, IntechOpen, London, 205-224. https://doi.org/10.5772/26404

[2] Field, A., Toba, A. and Ideozu, R.U. (2017) Reservoir Characterization and Prediction of Reservoir Performance Using 3-D D Static Modelling: Awe Field, Niger Delta, Nigeria. International Basic and Applied Research Journal, 3, 1-17.

[3] Yu, J.T., Xie, J., Meng, N.N. and Lin, P. (2011) 3D Geological Modeling in Chang 109 Block of Changchunling Oilfield. Advanced Materials Research, 204-210, 1891-1894. https://doi.org/10.4028/www.scientific.net/AMR.204-210.1891

[4] Al-Baldawi, B.A. (2015) Building A 3D Geological Model Using Petrel Software for Asmari Reservoir, South Eastern Iraq. Iraqi Journal of Science, 56, 1750-1762.

[5] Altameemi, A.M.H. and Alzaidy, A. (2018) Geological Modeling Using Petrel Software for Mishrif Formation in Noor Oil Field, Southeastern Iraq. Iraqi Journal of Science, 59, 1600-1613. https://doi.org/10.24996/ijs.2018.59.3C.7

[6] Bjorlykke, K. and Knut, B. (2015) Petroleum Geoscience from Sedimentary Environment to Rock Physics Second Edition. Springer-Verlag, Berlin, Heidelberg.

[7] Adeoti, L., Onyekachi, N., Olatinsu, O., Fatoba, J. and Bello, M. (2014) Static Reservoir Modeling Using Well Log and 3-D Seismic Data in a KN Field, Offshore Niger Delta, Nigeria. International Journal of Geosciences, 5, 93-106. https://doi.org/10.4236/ijg.2014.51011

[8] Agyare Godwill, P. and Waburoko, J. (2016) Application of 3D Reservoir Modeling on Zao 21 Oil Block of Zilaitun Oil Field. Journal of Petroleum \& Environmental Biotechnology, 7, 1-8. https://doi.org/10.4172/2157-7463.1000262

[9] Satter, A. and Iqbal, G.M. (2016) Determination of Oil and Gas in Place: Conventional and Unconventional Reservoirs.

https://doi.org/10.1016/B978-0-12-800219-3.00012-7

[10] Ahmed, T. (2010) Reservoir Engineering. Gulf Professional Publishing, Oxford.

[11] Zafar, A. and Fan, H.J. (2017) Combination of Geological, Geophysical and Reservoir Engineering Analyses in Field Development: A Case Study. International Journal of Environmental, Chemical, Ecological, Geological and Geophysical Engineering, 11, 36-43.

[12] Zafar, A., et al. (2019) The Numerical Simulation and Wellbore Modeling of Steam Injection and Stored Heat Recovery from Light Oil Reservoir. Energy Sources, Part A: Recovery, Utilization, and Environmental Effects. https://doi.org/10.1080/15567036.2019.1676331

[13] Zafar, A., et al. (2019) The Numerical Simulation of Effects of Porosity, Permeability and Fluid Saturation on Heat Dissipation in an Oil Reservoir. 2nd International Conference of Arabian Journal of Geosciences, Tunisia, 25-28 November 2019.

[14] Zafar, A., et al. (2020) Tight Gas Production Model Considering TPG as a Function of Pore Pressure, Permeability and Water Saturation. Petroleum Science. 
https://doi.org/10.1007/s12182-020-00430-4

[15] Kashif, M., Cao, Y., Yuan, G., et al. (2019) Sedimentological Impact on Reservoir Quality of Es1 Sandstone of Shahejie Formation, Nanpu Sag, East China. Arabian Journal of Geosciences, 12, 545. https://doi.org/10.1007/s12517-019-4671-y

[16] Fan, H.J., Zafar, A., et al. (2017) Analyses of Nature of Fault through Production Data. Open Journal of Yangtze Gas and Oil, 2, 176-190.

https://doi.org/10.4236/ojogas.2017.23014

[17] Zafar, A., et al. (2020) Heat Dissipation Modeling of In-Situ Conversion of Oil Shale. Open Journal of Yangtze Gas and Oil, 5, 46-53.

https://doi.org/10.4236/ojogas.2020.52005 